\title{
PRELIMINARY SHIELD DESIGN FOR A SNAP-8 POWER SYSTEM
}

I. M. Karp, L. Soffer and M. R. Clark

National Aeronautics and Space Administration Lewis Research Center.

Cleveland, Ohio

A preliminary shield design for a nuclear power system utilizing a SNAP-8 reactor for space base application is presented. A representative space base configuration was selected to set the geometry constraints impo sed on the design. The base utilizes two independent power packages each with a reactor operating at $600 \mathrm{kwt}$ and each producing about $50 \mathrm{kwe}$. The crew compartment is located about 200 feet from each reactor and is large enough in extent to intercept a total shadow angle of $60^{\circ}$ measured about the center line of each reactor.

Reactor dose constraints for the shield design were: (1) the do se to the crew over a 6 month mission was set at $150 \mathrm{mrem} /$ day, (2) the do se along the side of either power system was set at $30 \mathrm{mrem} / \mathrm{hr}$ at a distance of 200 feet, based on considerations of exposure during repair to one power system while the other is operating, and (3) the dose constraint elsewhere around the reactor was set at $5 \mathrm{rem} / \mathrm{hr}$ at a distance of 200 feet. Personnel are not expected to be in this region during operation of the power systems except possibly for very brief periods during approach and departure from the base.

The shield design presented incorporates the results of calculations and some preliminary engineering considerations. The weight of the idealized layered lithium hydride and depleted uranium shield layout used as the calculational model was about 35,000 pounds whereas the preliminary engineering layout of the shield which includes structure, canning materials, clearance gaps between layers, etc. weighed about 41,000 pounds.

\section{INTRODUCTION}

The SNAP-8 reactor has been designed as the heat source for a space nuclear power system. Several power conversion systems compatible with the SNAP-8 reactor have been built and tested. An important component that is still required for the system is a nuclear radiation shield designed to maintain a desired set of radiation do se constraints. The purpose of a shield design, in addition to providing the desired radiation constraints, is to provide a structure that is of minimum weight and will maintain its mechanical integrity over a desired lifetime. Although minimum shield weight is desired, some trade offs between weight and good engineering design are often required. Many calculations have been made of estimates of shield weights, however, little has been presented concerning an engineered design of such a shield.

At NASA Lewis Research Center a design study is being made of an engineered flight rated shield for the SNAP-8 power system for application on a space base. Many of the engineering aspects involved in this type of shield design were considered and are discussed in Ref. 1. The present paper presents a preliminary shield designed for a specific space base configuration and a selected set of dose constraints around the power system. These constraints were based mainly on crew do se constraints recommended by the Radiological Advisory Panel of the committee on Space Medicine of the Space Science Board, Ref. 2. This design incorporates the results of calculations which involved simplified parametric optimization studies as well as more sophisticated two dimensional transport analysis and some preliminary engineering considerations.

\section{SPACE BASE CONFIGURATION AND RADIATION SOURCES}

Configuration - The space base configuration considered for this study was one investigated in a McDonnelDouglas study, Ref. 3. The model cho sen for this study is shown in Fig. 1. The space base uses two SNAP-8 power systems, each mounted at the upper end of a 200 foot long boom. The booms meet at their lower ends and make an angle of $30^{\circ}$ with each other, so that the power systems are about 100 feet apart. The lower ends of the booms meet at the midpoint of the crew compartment which is 240 feet long. The crew compartment intercepts a total angle of $60^{\circ}$ with each power system.

Sources - The SNAP-8 reactor and the primary coolant loop are shown schematically in Fig. 2. The reactor operates at a power level of $600 \mathrm{kwt}$ and the system generates about 50 kwe. The primary coolant is $\mathrm{NaK}$ which removes heat from the reactor and releases this heat to an intermediate coolant in the heat exchanger.

The reactor operating at $600 \mathrm{kw}$ for a desired lifetime of five years is the main source of radiation that has to be shielded. The primary coolant loop containing activated $\mathrm{NaK}$ and possibly some leakage fission products is also an important radiation source that has to be shielded (the primary coolant has been estimated to contain 450 curies of $\mathrm{Na}^{24}, 180$ curies of $\mathrm{K}^{42}$, and 0.1 percent of the volatile fission products generated by the reactor).

In addition to the shield required around these sources to maintain desired dose constraints around the power system, there has to be sufficient shield between the reactor and primary loop components (pumps, heat exchangers, expansion tanks) which are located in a region called the gallery, so that the radiation limits of the 


\section{DISCLAIMER}

This report was prepared as an account of work sponsored by an agency of the United States Government. Neither the United States Government nor any agency Thereof, nor any of their employees, makes any warranty, express or implied, or assumes any legal liability or responsibility for the accuracy, completeness, or usefulness of any information, apparatus, product, or process disclosed, or represents that its use would not infringe privately owned rights. Reference herein to any specific commercial product, process, or service by trade name, trademark, manufacturer, or otherwise does not necessarily constitute or imply its endorsement, recommendation, or favoring by the United States Government or any agency thereof. The views and opinions of authors expressed herein do not necessarily state or reflect those of the United States Government or any agency thereof. 


\section{DISCLAIMER}

Portions of this document may be illegible in electronic image products. Images are produced from the best available original document. 
components are not exceeded, and the intermediate coolant is not activated to a serious level.

The reactor and pressure vessel are contained within a cylindrical region (reactor cavity) which is 24 inches in diameter and 32 inches high, around which the shield is placed.

A cylindrical shaped gallery 66 inches in diameter and 24 inches high is required to contain the primary loop components.

\section{DOSE CONSTRAINTS FROM NUCLEAR POWER SYSTEMS}

Dose in crew compartment - In order to establish dose constraints, it is assumed that the mission is to be of about six months duration, and further that the crew would not be exposed to any additional radiation for the following six months. The total permissible dose as recommended by the Radiobiological Advisory Panel, Ref. 2, for this exposure-time schedule is $70 \mathrm{rem}$. This dose is sufficiently large to permit a dose to the crew from the nuclear power systems of $150 \mathrm{mrem} /$ day $(6.2 \mathrm{mrem} / \mathrm{hr})$ and still leave an adequate allowance for the expected dose from natural radiation. This value of $150 \mathrm{mrem} /$ day is recommended as an upper limit in Ref. 2 and by the NASA Radiation Constraints Panel, Ref. 4.

The permissible dose rate from each power system (taking into account the space base geometry) varies from $3 \mathrm{mrem} / \mathrm{hr}$ at the center of the crew compartment (200 feet away) to $4 \mathrm{mrem} / \mathrm{hr}$ at one extremity (205 feet away) and $2 \mathrm{mrem} / \mathrm{hr}$ at the other extremity (260 feet away). Fig. 3 illustrates this exclusion region of half angle $30^{\circ}$ at a nominal distance of 200 feet.

Side dose constraint - The side do se rate constraint was based on considerations of maintenance on one shut down power system while the other is operating. The total dose to be received during this operation was arbitrarily set as 1 rem. Further assuming that the repair requires about 8 hours, the equivalent do se rate at a distance of 200 feet from the side of the shield is 30 $\mathrm{mrem} / \mathrm{hr}$. This region is shown in the figure as extending from a half angle of $30^{\circ}$ to $90^{\circ}$.

Above the shield a dose rate of $5.0 \mathrm{rem} / \mathrm{hr}(2.5 \mathrm{rem} /$ $\mathrm{hr}$ from each power system) at a distance of 200 feet was set as an upper limit. This region is shown in the figure as extending from a half angle of $90^{\circ}$ to $180^{\circ}$. The presence of personnel in this region is not anticipated except possibly for short periods during approach and departure from the base.

Coolant loop component constraints - The allowable radiation constraints to the primary coolant loop components (located in the gallery region) integrated over a lifetime of 5 years were:

$$
10^{10} \mathrm{rad} \text { gamma dose and a fluence of }
$$$$
10^{18} \mathrm{neut} / \mathrm{cm}^{2} \text { of } \mathrm{E}>0.1 \mathrm{MeV}
$$

\section{CALCULATIONAL PROCEDURE}

In general, the method employed at Lewis Research Center for the shield design is as follows:

1. A parametric study is first made to determine the best reactor-gallery orientation, the shield materials, the number of shield layers, an estimate of their thicknesses and their arrangement around the sources.
2. A two-dimensional transport analysis is made of the shield selected in step 1 to check heating rates and dose rates within and around the shield.

3 . The effects of shield penetrations and three dimensional geometry on radiation leaking out of the shield are then analyzed.

4. A fairly detailed engineering layout is made and from this another two-dimensional calculational model is constructed and further analyzed (iterations of steps 2 and 3).

The parametric study step 1 involves a multiplicity of layouts to be investigated and so requires simpler and more rapid methods of shield radiation transport calculations. Briefly, for each layout, the method involves determining the shield weight as a function of all shield layer thicknesses for the actual distribution of layers around a reactor and gallery orientation. One-dimensional transport calculations are made using the ANISN code, Ref. 5, to estimate the do ses and change in doses with any change in shield layer thickness in either the radial or axial directions. These doses and weights and their changes with every shield layer thickness are input into an optimization code, D'OPEX. This code uses the method of steepest descent to determine the optimum set of thicknesses for a desired set of radial and axial dose constraints which are also input into the code. D'OPEX is the NASA Lewis extension of an Atomics International code OPEX, Refs. 6 and 7.

Some engineering design considerations are also factored into the parametric study, for example heating rates and fabricability can affect the material selection and layer arrangement.

The two dimensional analysis of the shield uses the two dimensional transport code DOT, Ref. 8 , to evaluate dose and heating rates and fluxes throughout the shield. A code, MAP, Ref. 9, which utilizes the angular fluxes at the outer surface of the shield is used to calculate doses at distant detectors. The results of this phase of the analysis indicate whether any revisions to the shield are necessary (either additions to reduce doses at certain locations, or removal to increase doses or redisribution of shield to further optimize the shield weight). An iteration of the transport calculations is required to check the effects of the se shield revisions.

To analyze the effects of shield penetrations and complex geometry, either a Monte Carlo approach or other methods are applied locally to the region of the irregularity to estimate the effect on radiation leakage out of a shield surface region as compared to that of the unperturbed two dimensional transport analysis. Revisions to the shield necessitated by these effects are then estimated.

The engineering layout of the shield based on the forgoing computational model includes additional materials such as structure and canning material. These additional materials, clearance gaps, and changes in the shape of some shield layers necessitated by fabrication limitations, result in the engineering layout being larger in size than the computational shield model.

\section{RESULTS AND DISCUSSION}

As seen in Fig. 3 the crew region intercepts a half angle of $30^{\circ}$ with the axis of the reactor-shield assembly. 
Because for the present system, the side do se constraint is only a factor of ten greater than the crew do se constraint for each reactor, it was decided to base the shield weight optimization on a cylindrical shaped shield model rather than a shadow shaped shield model. This shape would simplify the engineering design.

\section{Parametric Study}

From the parametric study it was determined that:

1. The gallery located above the reactor (away from crew) resulted in lower shield weight.

2. Depleted uranium was to be used for gamma shield material and lithium hydride for neutron shield material.

3. Depleted uranium could not be used as the first layer (where it would be in a very high flux region) because the high fission rate produced excessive heating in the layer.

4. There was less than one percent effect on total shield weight if lithium hydride was used as the first layer instead of heavy gamma material.

5. For the thick shields required, five shield layers both radially and axially toward the crew were an optimum number; three layers were sufficient between the reactor and gallery.

For the cylindrical shaped shield, it was estimated that to obtain a dose of $4 \mathrm{mrem} / \mathrm{hr}$ at the extremity of the crew region ( $30^{\circ}$ position), an axial do se constraint of $1 \mathrm{mrem} / \mathrm{hr}\left(0^{\circ}\right.$ po sition) and a radial do se constraint of $30 \mathrm{mrem} / \mathrm{hr}\left(90^{\circ}\right.$ position) were required (the latter consisting of $15 \mathrm{mrem} / \mathrm{hr}$ from the gallery source and $15 \mathrm{mrem} / \mathrm{hr}$ from the reactor and secondary sources). These axial and radial constraints were used in the D'OPEX code to determine the specific layer thicknesses.

The results of the parametric study are presented in Fig. 4 which shows the various shield layers arranged around the reactor and gallery in a symmetrical twodimensional configuration. The radial and axial layers are connected together by ellipsoids of revolution.

\section{Two-Dimensional Analysis of Initial Shield Configuration}

The two-dimensional calculations were performed in two separate parts. One calculation involved the transport of the primary coolant gamma source which was assumed to be distributed uniformly over the gallery region. The other calculation involved the transport of the reactor sources which included the generation and transport of secondary sources throughout the shield. Due to the size of the problem the spatial mesh size, angular quadrature, and scatter order, had to be relaxed from tho se typically used in the one-dimensional transport calculations made in the parametric study. The values used in the two-dimensional DOT calculations were as follows:

1. For the gallery gamma calculation, 15 energy groups, P-2 scatter order, S-8 angular quadrature, and 43 radial by 47 axial spatial mesh intervals. Only the top half of the configuration (above the reactor and shield midplane) was considered for this calculation.
2. For the reactor calculation, 26 neutron energy groups coupled with 15 gamma energy groups, P-2 scatter order, S-6 angular quadrature, and 43 radial by 88 axial spatial mesh intervals, were used.

Results from this initial two-dimensional shield calculation are presented in Figs. 5 and 6 . Dose rates were evaluated at detectors positioned around the shield at a reference distance of 200 feet as shown in Fig. 5. The dose rate values are also presented in the figure. Dose rates in the crew compartment vary from $1.4 \mathrm{mrem} / \mathrm{hr}$ at $0^{\circ}$ to $7.7 \mathrm{mrem} / \mathrm{hr}$ at $30^{\circ}$; along the side from 7.7 $\mathrm{mrem} / \mathrm{hr}$ at $30^{\circ}$ to $41.3 \mathrm{mrem} / \mathrm{hr}$ at $90^{\circ}$; elsewhere from 41.3 at $90^{\circ}$ to a peak value of $510 \mathrm{mrem} / \mathrm{hr}$ at $180^{\circ}$.

The crew constraint is exceeded in the crew compartment in the range from about $15^{\circ}$ to $30^{\circ}$ and the side constraint is exceeded in the region from $70^{\circ}$ to $90^{\circ}$. In the region from $90^{\circ}$ to $180^{\circ}$ the doses are well within the constraint of $2.5 \mathrm{rem} / \mathrm{hr}$. These results indicated that shield revisions were necessary.

\section{Revisions to Shield}

As part of the calculations, contributions to the dose at each detector from radiation leaking out of various portions of the shield surface were determined. This information was useful to help guide where adjustments to the layered shield should best be made. Fig. 6 shows the outline of the shield surface and the portions of the surface of the DOT calculation model (labelled I - VIII) that were investigated. The figure also presents the neutron, reactor and secondary gamma, and gallery gamma dose contributions from each surface region for detectors at $30^{\circ}$, and $90^{\circ}$.

The high gallery gamma contribution to the $90^{\circ} \mathrm{de}-$ tector from surface VIII indicated that additional shield was required along the side of the gallery. The high gallery contributions to the $30^{\circ}$ detector from surfaces VII and VIII were also due to inadequate shield along the side of the gallery. High gallery contributions from surfaces V and VI indicated that the connecting piece of uranium between the gallery side shield and outer radial uranium layer was not sufficiently thick. The reactor and shield gamma do se contribution from the surfaces II and III to the $30^{\circ}$ detector were also excessive and indicated that the connecting ellipsoids at the corners of the uranium layers needed thickening. Relatively large neutron dose contributions from surfaces VII and VIII to the $30^{\circ}$ detector, and from surface VIII to the $90^{\circ}$ detector indicated that there was appreciable scattering of neutrons by the gallery side shield. In addition to analyzing these surface contributions, plots of gamma and neutron isodose lines throughout the shield were also used to guide shield revisions.

The revisions made to the shield shown in Fig. 4 were as follows:

1. The gallery side shield thickness was increased from $2.2 \mathrm{~cm}$ to $3.0 \mathrm{~cm}$.

2. The outer radial uranium layer thickness was increased from $2.0 \mathrm{~cm}$ to $2.5 \mathrm{~cm}$.

3. The connecting piece of uranium between these was thickened proportionately.

4. The entire ellipsoidal corner of the outer uranium layer was thickened by an average of about $1.5 \mathrm{~cm}$. 
5. The uranium layer between the reactor and gallery was reduced in thickness from $5.2 \mathrm{~cm}$ to $4.2 \mathrm{~cm}$.

A two-dimensional transport calculation of the revised shield was made and the results are shown in table I. The dose rates in the crew region now range from 0.8 $\mathrm{mrem} / \mathrm{hr}$ at $0^{\circ}$ to $3.6 \mathrm{mrem} / \mathrm{hr}$ at $30^{\circ}$ and are within the permissible crew constraint everywhere. The dose rates along the side of the power system vary from $3.6 \mathrm{mrem} /$ $\mathrm{hr}$ at $30^{\circ}$ to about $23 \mathrm{mrem} / \mathrm{hr}$ at $90^{\circ}$, and are within the permissible side constraint. Above the gallery, in the $90^{\circ}$ to $180^{\circ}$ region the maximum do se rate is about 0.6 $\mathrm{rem} / \mathrm{hr}$, well within the desired constraint of $2.5 \mathrm{rem} / \mathrm{hr}$.

Radiation dose levels in the gallery were calculated to be $3 \times 10^{8} \mathrm{rad}$ gammas and $2 \times 10^{14}$ neuts $/ \mathrm{cm}^{2}, \mathrm{E}>0.1$ Mev, over a 5 year period. These are well within the allowable constraints.

The weight of the revised shield configuration used as the calculation model is 35,000 pounds.

\section{Engineering Design Considerations}

The results of the shield analysis discussed so far were used to produce an engineered layout of the shield. In this layout, considerations of shield cooling, structural support for the entire shield, containment for the shield materials as well as fabrication of the shield layers, clearances between layers, the assembly of the entire shield, etc. were taken into account.

A simplified sketch of the engineered layout which shows some of the features of the design is shown in Fig. 7. Although some of the uranium layers are utilized as structural members, much additional steel structure is required. Shown in the figure are also the coolant ducts, control drum actuator penetrations, and about a 1/2-inch clearance gap between the removable and stationary portions of the shield. This latter feature was designed into the shield for replacement of the reactor when required. A portion of the shield which contains the reactor is removable. Thus the replacement package contains the new reactor and only a fraction of the entire shield. A sketch of this replaceable section with respect to the permanent section of the shield is shown in Fig. 8 . Incidentally, although the actuator shaft penetrations enhance the radiation streaming toward the crew, their location in this position in the shield make them accessible for repair.

The structure, canning materials, and clearances, as well as some revisions in the shield layer shapes, necessitated by fabrication considerations, result in the engineering layout being larger in size and weight than the computational model of the shield. As a comparison, the engineered layout shown in Fig. 7 weighs 41,000 pounds compared to a weight of 35,000 pounds for the revised computational model.

\section{CONCLUDING REMARKS}

A preliminary shield design for a SNAP-8 nuclear power system has been evolved to meet a set of selected dose constraints for a specific space base configuration. This design incorporates results of calculations involving a preliminary parametric optimizational study, iterated two-dimensional transport analysis, and some engineering design considerations. The weight of the idealized computed shield configuration is 35,000 pounds. This compared to a weight of 41,000 pounds for an engineered shield layout.

Before the design can be finalized, the effects of shield penetrations and any changes in the shield geometry necessitated by these has yet to be determined and incorporated into the engineered layout. A calculational model of the shield based on the engineered layout has to be made and two dimensional transport calculations of this configuration performed. As the design becomes finalized finer spatial mesh size, angular quadrature, and scattering order should be used in the calculations in order to improve the accuracy of the design.

\section{TABLE I. - DOSE RATES AROUND REVISED SHIELD CONFIGURATION}

$\begin{array}{cccr}\begin{array}{c}\text { Detector } \\ \begin{array}{c}\theta \\ \text { degree }\end{array}\end{array} & \begin{array}{c}\text { Reactor } \\ \text { dose } \\ \text { mrem/hr }\end{array} & \begin{array}{c}\text { Gallery } \\ \text { dose } \\ \text { mrem/hr }\end{array} & \begin{array}{c}\text { Total } \\ \text { dose } \\ \text { mrem } / \mathrm{hr}\end{array} \\ 0 & 0.8 & --- & 0.8 \\ 10 & 1.2 & 0.1 & 1.3 \\ 20 & 1.9 & 0.3 & 2.2 \\ 30 & 2.7 & 0.9 & 3.6 \\ 40 & 4.1 & 2.0 & 6.1 \\ 50 & 5.6 & 3.9 & 9.5 \\ 60 & 7.3 & 6.3 & 13.6 \\ 70 & 8.8 & 9.1 & 17.9 \\ 80 & 10.3 & 11.4 & 21.7 \\ 90 & 11.4 & 11.8 & 23.2 \\ 120 & 30 . & 145 . & 175 . \\ 150 & 295 . & 225 . & 520 . \\ 180 & 360 . & 245 . & 605 .\end{array}$




\section{REFERENCES}

1. Kaszubinski, Leonard J.; Kacher, Henry F.; and Odar, Fred: Preliminary Designs of Space Power Nuclear Reactor Shields. NASA TM X-2038, 1970.

2. Radiobiological Advisory Panel, Committee on Space Medicine, Space Science Board: Radiation Protection Guides and Constraints for Space-Mission and Vehicle-Design Studies Involving Nuclear Systems. National Academy of Sciences, 1970 .

3. McKhann, G. G.; Coggi, J. V.; and Diamond, S. D.: Preliminary Design of Reactor Power Systems for the Manned Space Base. Paper WD 1296, McDonnell Douglas Astronautics Co., June 1970.

4. Space Station Task Group: Guidelines and Constraints Document Space Station Program Definition Phase B. MSC-00141, Rev. N, NASA Manned Spacecraft Center, Apr. 24, 1970.

5. Engle, Ward W., Jr.: A Users Manual for ANISN: A One-Dimensional Discrete Ordinates Transport Code with Anisotropic Scattering. Rep. K-1693, Union Carbide Corp., Mar. 20, 1967.

6. Bernick, R. L.: The OPEX Shield Optimization Code. Rep. NAA-SR-Memo11516, Atomics International, July 13, 1965.

7. Lahti, Gerald P.: Opex-I, A Radiation Shield Optimization Code. NASA TM $\mathrm{X}-1769,1969$.

8. Soltesz, R. G.; Disney, R. K. ; and Collier, G.: User's Manual for the DOT-IIW Discrete Ordinates Transport Computer Code. Rep. WANL-TME-1982, Westinghouse Astronuclear Lab., Dec. 1969.

9. Disney, R. K.; Soltesz, R. G.; Jedruch, J.; and Zeigler, S. L.: Code Description and User's Manual for the MAP Radiation Transport Computer Code. Rep. WANL-TME-2706, Westinghouse Astronuclear Lab., Aug. 1970.

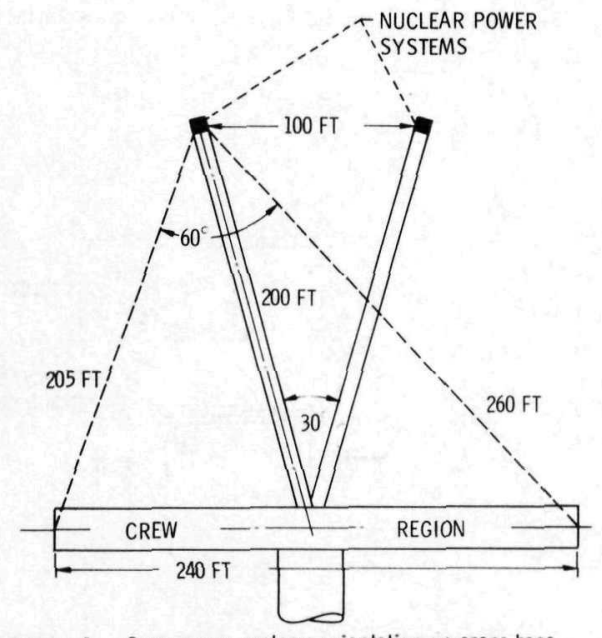

Figure 1. - Crew-power systems orientation on space base.

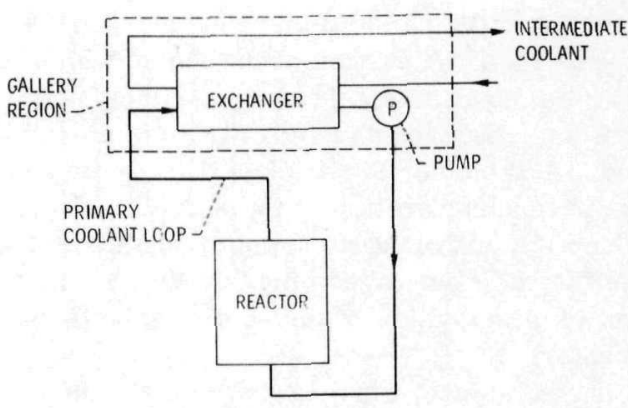

REACTOR $600 \mathrm{kIV}$ - 5 YR OPERATION

GALLERY $\left\{\begin{array}{l}450 \text { CURIES Na } \\ 180 \text { CURIES } K^{24}\end{array}\right.$

0. 1 PERCENT OF VOLATILE FISSION PRODUCTS

Figure 2. - Reactor and primary coolant sources. 


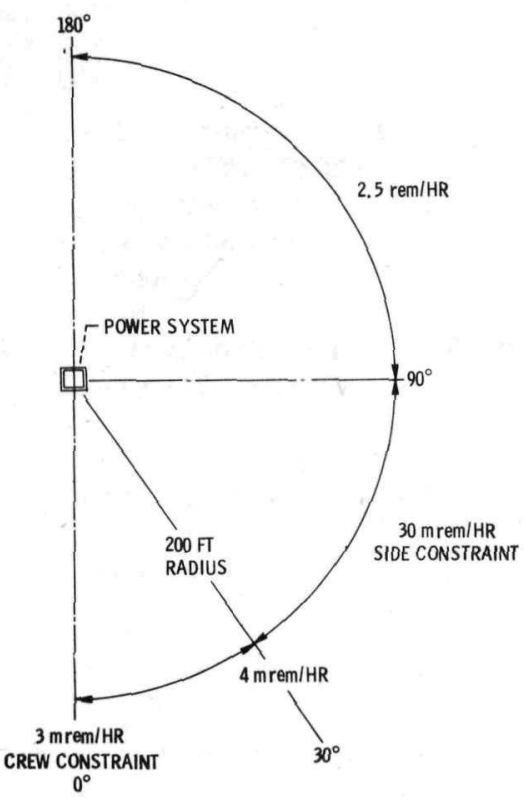

Figure 3. - Dose constraint map around each power system.

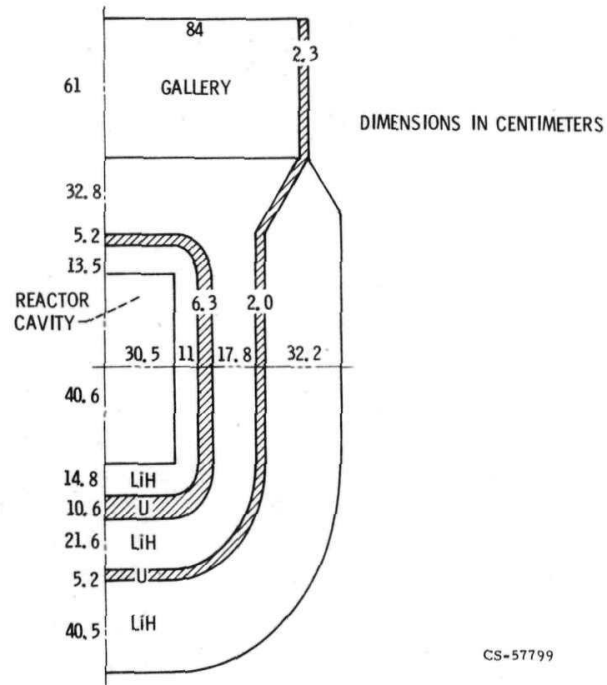

Figure 4. - Initial shield layering around reactor and gallery sources.

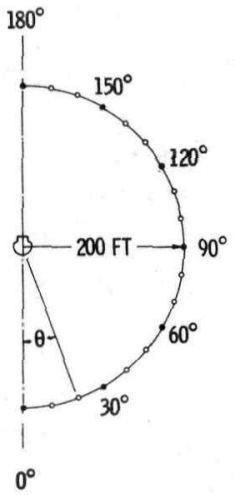

DETEC
$\theta$,
DE

10
20
30
40
50
60
70
80
90
120
150
180

Figure 5. - Dose rates around initial shield configuration

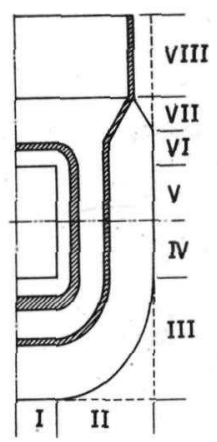

\begin{tabular}{|c|c|c|c|c|c|c|}
\hline \multirow[t]{3}{*}{ SURFACE } & \multicolumn{3}{|c|}{$30^{\circ}$} & \multicolumn{3}{|c|}{$90^{\circ}$} \\
\hline & \multicolumn{2}{|c|}{ REACTOR } & \multirow{2}{*}{$\begin{array}{c}\text { GALLERY } \\
\gamma\end{array}$} & \multicolumn{2}{|c|}{ REACTOR } & \multirow{2}{*}{$\begin{array}{c}\text { GALLERY } \\
\gamma\end{array}$} \\
\hline & NEUT & $\gamma$ & & NEUT & $\gamma$ & \\
\hline I & 0.03 & 0.2 & $-\cdots$ & --- & --- & $-\cdots$ \\
\hline II & .08 & 1.5 & $\cdots$ & $\cdots$ & -- & $-\cdots$ \\
\hline III & .13 & 1.2 & $\cdots$ & .1 & 0.6 & $-\cdots$ \\
\hline IV & .29 & .8 & -- & 1.2 & 5.6 & $-\infty$ \\
\hline V & .15 & .18 & 1.1 & .8 & 2.8 & 0.2 \\
\hline VI & .05 & .08 & .5 & .2 & .7 & .4 \\
\hline VII & .17 & .04 & .5 & .1 & .3 & 3.3 \\
\hline VIII & .17 & .04 & .4 & 1.2 & .7 & 23.2 \\
\hline
\end{tabular}

Figure 6. - Dose contributions to detectors at $30^{\circ}$ and $90^{\circ}$ from various portions of the shield surface.

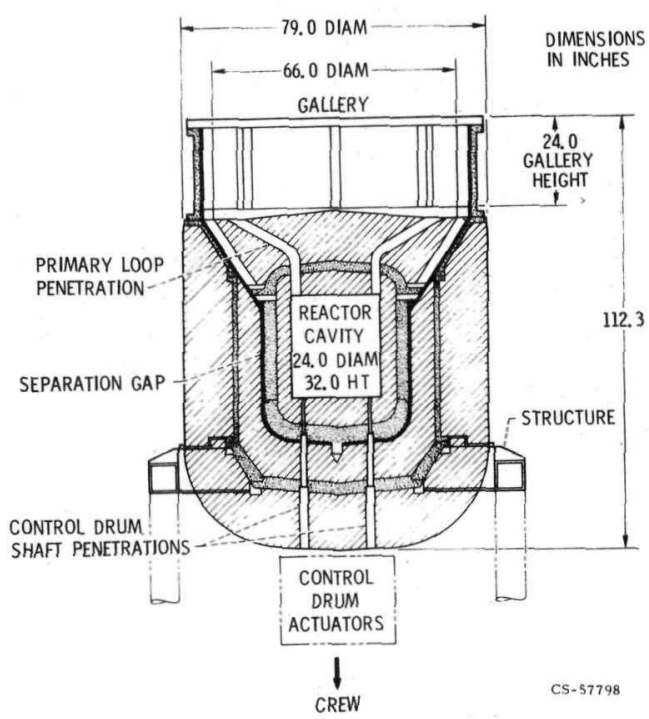

Figure 7. - Some features of the engineering layout of the shield.
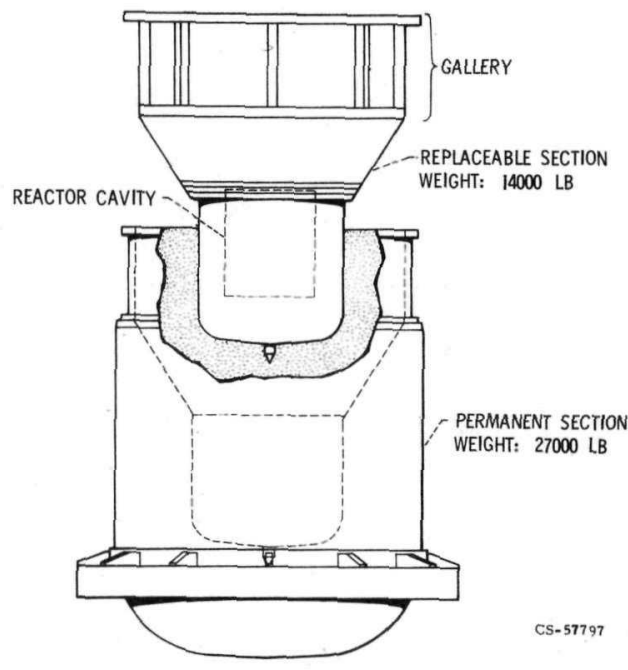

Figure 8. - Replaceable and permanent shield sections. 